\title{
Chagas Disease - Past and Future
}

\author{
Aurea Lúcia Alves de Azevedo Grippa de Souza ${ }^{\left({ }^{(}\right)}$and Claudio Tinoco Mesquita
}

Hospital Universitário Antônio Pedro, HUAP-EBSERH-UFF, Niterói, RJ - Brazil

"Remember to look up at the stars and not down at your feet. Try to make sense of what you see and wonder about what makes the Universe exist. Be curious."

Stephen Hawking

After 111 years of its discovery, Chagas disease remains a major public health challenge in Brazil and in other Latin American countries, reason why it continues to be a relevant topic in discussion panels worldwide. ${ }^{1}$ The disease was first described in 1909 by Carlos Justiniano Ribeiro das Chagas after his observations during an expedition to eradicate malaria in the rural areas of the state of Minas Gerais, in the city of Lassance. ${ }^{2}$ Carlos Chagas' magnificent life journey makes him a unique figure in the history of medicine, as he alone described all the stages of a new infectious disease: pathological findings, means of transmission (Triatoma infestans), etiology, clinical manifestations, and epidemiology. For this reason, he was one of the few Brazilians to be nominated for a Nobel Prize, which, unfortunately, he did not win. This issue of the International Journal of Cardiovascular Sciences (IJCS) focuses on Chagas disease and its repercussions on the cardiovascular system.

Carlos Chagas graduated in 1904 in Rio de Janeiro and began his professional life in the city of Niterói as a physician of the Public Hygiene Committee at Santa Isabel Maritime Hospital, after declining Oswaldo Cruz's invitation to work at Manguinhos. The Maritime Hospital, a beautiful architectural complex (Figure 1a) built during the 19th century from an old farm, was

\section{Keywords}

Chagas disease, Carlos Chagas, Trypanosoma Cruzi, Heart Failure; Percutaneous Coronary Intervention; Platelet Aggregation; Women; Aging; Myocardial Infarction. considered a reference for the treatment of infectious diseases until the end of the 4 th decade of the 20th century. ${ }^{3}$ Sailors, immigrants and local residents with bubonic plague, yellow fever or tuberculosis were treated at the institution. In this hospital, the Italian physician Camillo Terni, from the Serum Therapy Institute of Messina, conducted pioneering studies on a plague vaccine (Figure 1b). ${ }^{4}$ After working for 1 year at the Maritime Hospital, Chagas left to Manguinhos, where he began his journey to eradicate yellow fever and malaria, which led him to discover the disease caused by the insect known as barbeiro (kissing bug). ${ }^{2}$

Currently, Chagas disease is endemic in the Americas, with sporadic cases in Europe and Asia resulting from migratory processes. Bolivia, Argentina, Paraguay and Ecuador are the countries with the highest prevalence rates. Public policies implemented to control the disease since the 1980s have resulted in a decrease in prevalence in Brazil, dropping from $7 \%$ in the 1970 s to $0.17 \%$ nowadays. However, it is estimated that Argentina and Brazil (with about 1.3-1.5 million people infected) and Mexico and Bolivia (with about 0.6-0.8 million people infected) are the countries with the largest infected populations, for a total of more than 40000 new annual cases due to vector transmission and more than 14000 due to congenital transmission, ${ }^{5-8}$ In Brazil, efforts to control the spread of the disease have been intensified since the 1980s with the implementation of a national program. With the development of studies on Trypanosoma sp prevention and contamination, actions have been implemented in blood product transfusions, organ transplants, laboratory sample-handling procedures, and foodhandling practices associated with transmission as well as in congenital transmission. ${ }^{5}$ These actions have also been implemented in other Latin American countries, especially regarding the prevention of congenital 
transmission, which is currently an important form of transmission. Therefore, resources have been directed toward, but not limited to, molecular diagnosis in order to develop algorithms representative of the situation of infecting Trypanosoma cruzi strains in pregnant women and their potential maternal-fetal transmission. ${ }^{8}$

The World Heart Federation (WHF) has included Chagas disease in its roadmap project in view of serious cardiac complications, constant migratory flows of populations, and the need to prevent the spread of the disease not only in the Americas but also in the rest of the world. This action also aims to improve the allocation of resources for research into the development of new forms of laboratory diagnosis, vaccines, and drugs for treatment. The roadmap project proposes, by identifying roadblocks along the way, strategies and evidencebased solutions for health care professionals, health authorities, and governments to help overcome the barriers to a better understanding and comprehensive care in Chagas disease. ${ }^{9}$

In the last 20 years, approximately 12000 documents on Chagas disease, including articles and guidelines, have been published in MEDLINE journals. The importance of this topic is also reflected in special journal issues dedicated entirely to Chagas disease. ${ }^{10}$ The changes bring to light individual susceptibility to T. cruzi infection, development of biomarkers to monitor disease progression, production of new drugs, and control of transmission. These actions should be extremely effective in controlling the disease, with a great socioeconomic impact in Latin America. ${ }^{11}$ Research in this field will certainly contribute to the development of a vaccine by providing a better understanding of the diversity of the more than 140 subtypes of T. cruzi and the effects triggered in autoimmunity. Many needs are yet to be met in Chagas disease (Table 1).

Greater investment is needed in the Americas to increase awareness of the silent progression of Chagas disease, since symptoms of chronic impairment may take decades to manifest, especially cardiac complications. Improvements in general sanitation and housing conditions should form the basis of government public policies. However, the socioeconomic implications of this silent disease are often underestimated due to neglected observation, support and treatment for populations living with the disease, whether endemic or not. Efforts to eradicate Chagas disease require a multidisciplinary approach, tailored to local conditions and supported by medical and lay societies, which recognizes that reducing poverty, improving housing conditions and promoting cultural and educational actions have a direct impact on the incidence and prevalence not only of the disease itself but also of the chronic conditions associated with it, such as heart failure. In this special issue, the IJCS promotes a forum for a better understanding of Chagas disease and encourages continued basic and clinical research in the topic by using the above-quoted words of the physicist Stephen Hawking as a guide.

Table 1: Areas in Need of Research and Development in Chagas Disease

\begin{tabular}{|c|c|}
\hline Research and Development Area & Expected impact \\
\hline More accurate diagnostic tests & Reduction in the need to repeat tests and in diagnostic uncertainty \\
\hline Techniques to monitor the progression of Chagas disease & $\begin{array}{l}\text { Improvements in risk stratification and follow-up to } \\
\text { aid in intervention decision-making }\end{array}$ \\
\hline Vaccine development & Disease prevention in high-risk areas \\
\hline Development of more effective drugs & Improvement in clinical outcomes with reduced side effects \\
\hline $\begin{array}{l}\text { Development of strategies for better management of } \\
\text { advanced cases of heart disease }\end{array}$ & $\begin{array}{l}\text { Reduction in the risk of disease reactivation after transplant } \\
\text { and in morbidity and mortality with device therapies }\end{array}$ \\
\hline
\end{tabular}



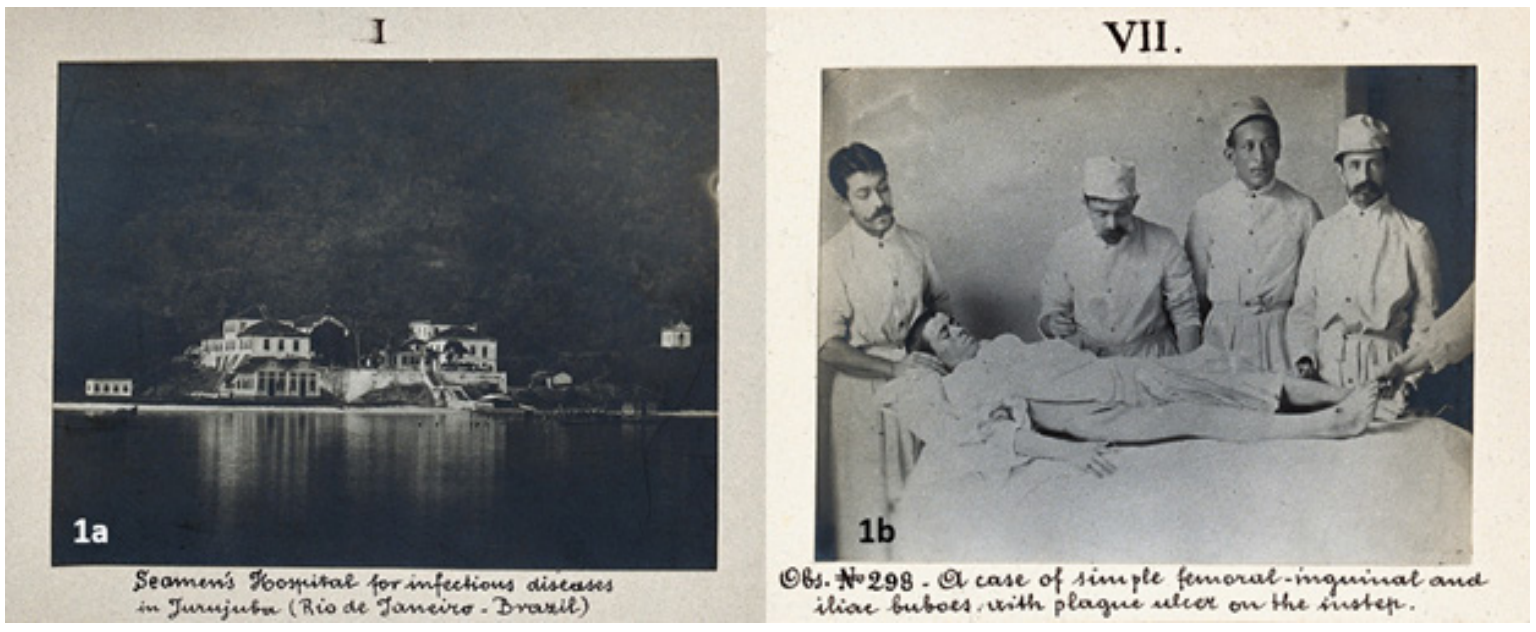

Figure 1 - Photographs from the collection of the University of Cambridge, with permission for reproduction. The photographs are personal records of Professor Camillo Terni during his stay at Santa Isabel Maritime Hospital between 1901 and 1905. 1a - View of the architectural buildings, known today as Casa da Princesa (Princess House). 1b - Photographic record of a bulb biopsy - Professor Camillo Terni at the center and his work team, which included Carlos Chagas.

\section{References}

1. Mesquita ET, Souza ALAAG, Rassi S. Dia de Alerta da Insuficiência Cardíaca: Um Tributo ao Gênio Carlos Chagas. Arq Bras Cardiol.2019;113(1):5-8.

2. Lidani, KCF; Andrade, FA; Bavia, L, Chagas Disease: from discovery to a worldwide health problem. Front Public Health. 2019;166(7):113.166(7):1-13.

3. Souza ALAG, Torbey AFM;,Paiva MAP, Mesquita ET. Anais Acad Nac Medicina 2019.190(3):76-8.

4. Silva MAD. De Bombaim ao Rio de Janeiro: circulação de conhecimento e a criação do Laboratório de Manguinhos, 1894-1902. História, Ciências, Saúde - Manguinhos, Rio de Janeiro, 2018, 25(3):639-57.

5. Corassa RB, Aceijas C, Alves PAB Evolution of Chagas' disease in Brazil. Epidemiological perspective and challenges for the future: a critical review. Perspectives in Public Health 2016,137(5):289-95.

6. Santos EF, Silva AOA, Leony LM, Freitas N, Daltro R, Regis-Silva CG, et al. Acute Chagas disease in Brazil from 2001 to 2018: A nationwide spatiotemporal analysis. PLoS Negl Trop Dis 2020,14(8): e0008445.
7. Pinazo MJ, Pereiro A, Herazoc R, Chopita M, Forsyth C, Lenardon M, et al. Interventions to bring comprehensive care to people with Chagas disease: Experiences in Bolivia, Argentina and Colombia. Acta Tropica. 2020;2003:105290.

8. Picado A, Cruz I, Redard-Jacot M, Schijman AG, Torrico NF. The burden of congenital Chagas /disease and implementation of molecular diagnostic tools in Latin America. BMJ Glob Health. 2018;3:e001069.

9. Echeverría LE, Marcus R, Novick G, Sosa-Estani S, Ralston K, al. WHF IASC Roadmap on Chagas Disease. Global Heart. 2020;15(1):26.

10. Nannetti FG, Molina I, Sosa-Estani S. New advances in the treatment of Chagas Disease. [Acesso em 2020 Out 12]. Disponível em https://www. sciencedirect.com/journal/acta-tropica/special-issue/10W7BP5STFF.

11. Acosta-Herrera M, Straussb M, Casares-Marfila D. Genomic medicine in Chagas Disease.. Acta Tropica. 2019;197:105062. 